\title{
Chemoprevention of Prostate Cancer: Myths and Realities
}

\author{
Philippe D. Violette, MD, and Fred Saad, MD
}

Background: Prostate cancer will affect $15 \%$ to $18 \%$ of men in North America and will result in death in $3 \%$. Established curative and palliative treatments for prostate cancer are associated with significant morbidity and cost. For these reasons, prostate cancer is an ideal target for prevention.

Methods: Using MEDLINE we performed a systematic review of clinical trials that have investigated pharmaceutical or nutritional interventions for the prevention of prostate cancer. The available evidence was critically evaluated and summarized according to the strength of recommendation taxonomy.

Results: Many pharmaceutical and nutritional interventions have been investigated for the prevention of prostate cancer. The strongest evidence exists to support the use of $5 \alpha$-reductase inhibitors (5-ARIs) for prevention of prostate cancer. However, the evidence is insufficient to recommend that these agents be used routinely among all men. In addition, the optimal timing or duration of 5-ARI use in not known. At present there is no suitable evidence to recommend using any specific nutritional supplement or diet to prevent prostate cancer.

Conclusions: Prostate cancer prevention should not be offered systematically to all men. There may be a role for 5-ARI use among motivated men who wish to take a proactive approach to prostate cancer prevention. (J Am Board Fam Med 2012;25:111-119.)

Keywords: Cancer Screening, Men's Health, Prostate, Urology

Prostate cancer is extremely common, affecting $15 \%$ of white men and $18 \%$ of African American men throughout their lifetime, and it will result in death in $3 \%$ of men in North America. ${ }^{1}$ The disease is comparable to breast cancer, which will affect $12 \%$ women throughout their lifetime ${ }^{2}$ and cause death in $3 \%{ }^{3}$ There are established curative treatments for prostate cancer such as prostatectomy and radiotherapy (with or without androgen ablation), which have shown a survival benefit when compared with observation with delayed treatment. ${ }^{4-6}$ There also are many palliative treatments

This article was externally peer reviewed.

Submitted 11 April 2011; revised 27 August 2011; accepted 2 September 2011.

From the Division of Urology, McGill University Health Centre (PDV); and Division of Urology, Centre Hospitalier de l'Université de Montréal (FS), Montreal, Quebec, Canada.

Funding: none.

Conflict of interest: Dr. Saad has acted as an advisor for and has done research in the past with GlaxoSmithKline. However, this review was performed completely independently.

Corresponding author: Fred Saad, University of Montreal, 1560 Sherbrooke East, Montreal, Quebec, Canada, H2L 4M1 (E-mail: fredsaad@videotron.ca). such as hormonal therapy, ${ }^{7}$ chemotherapy. ${ }^{8}$ and several new innovative treatments for advanced prostate cancer. ${ }^{9-11}$ However, these treatments, whether curative or palliative in intent, are associated with significant morbidity ${ }^{12}$ as well as increasing cost. ${ }^{13}$ The ubiquitous nature of the disease as well as the significant burden of treatment makes prostate cancer an ideal target for prevention. Preventing or delaying onset of disease potentially could result in reduced morbidity and cost related to prostate cancer and its treatments.

Many potential interventions have been proposed for the prevention of prostate cancer. These interventions include medications $(5-\alpha$ reductase inhibitors, nonsteroidal anti-inflammatory drugs [NSAIDs], Cox 2 inhibitors, selective estrogen receptor modulators [SERMs], statins); dietary supplements (vitamins A, C, D, and E, selenium, calcium, multivitamins, folic acid, lycopene, soy and related isoflavanoids, green tea and related polyphenols, omega $3 / 6$ fatty acids); and dietary interventions (soy, fat, protein, and fish consumption). From these possible interventions there have been 3 large, well-designed, randomized controlled trials 
(RCTs) published: the Prostate Cancer Prevention Trial (PCPT) ${ }^{14}$ the Reduction by Dutasteride of Prostate Cancer Events (REDUCE) trial, ${ }^{15}$ and the Selenium and Vitamin E Cancer Prevention Trial (SELECT),${ }^{16}$ which have provided the most robust evidence for prostate cancer prevention. In this article we will review the available literature about chemoprevention of prostate cancer and provide a recommendation based on this evidence.

\section{Methods}

We performed a review of clinical trials that have investigated pharmaceutical or nutritional interventions for the prevention of prostate cancer. We searched MEDLINE (using Ovid) and PubMed for articles published from 1996 to August 2010. We identified studies that focused on the use of medications, nutritional supplements, and dietary interventions in the prevention of prostate cancer. We also used the American Cancer Society and $\mathrm{Na}$ tional Cancer Institute websites to gather information about cancer statistics.

We used combinations of the following Medical Subject Headings terms: chemoprevention, primary prevention, prostatic neoplasms, testosterone $5-\alpha$ reductase, finasteride, SERMs, vitamins, antioxidants, vitamin $\mathrm{E}$, vitamin $\mathrm{D}$, ascorbic acid, carotenoids, soy milk, soy foods, isoflavones, plant extracts, diet, omega 3 fatty acids, omega 6 fatty acids, dietary proteins, dietary fats, antilipemic agents, anticholesterolemic agents, hydroxymethylglutarylcoenzyme A reductase inhibitors, hydroxymethylglutaryl- coenzyme A reductases. All searches were limited to humans and English language.

In our initial search strategy we did not impose any restriction on the type of study design, and we made an effort to include relevant meta-analyses, review articles, and RCTs. We retained the following types of studies: meta-analyses; RCTs; clinical trials (phase III, IV, multicenter, or single center); practice guidelines; epidemiologic studies; case-control studies; and cohort studies. We identified additional studies by searching manually through references of related review articles and landmark clinical trials. Titles and abstracts identified by the literature search were assessed for eligibility. Studies that could not be excluded based on information contained within the abstract were retrieved in full for further evaluation.

Our search strategy yielded 490 citations. After examining titles and abstracts of the retrieved cita- tions a total of 56 met our inclusion criteria and were included. We identified an additional 5 articles from review of the references of landmark trials and review articles. Articles were excluded because the study was pre-clinical, there were no relevant outcome data, the citation was an editorial comment, or the article described a research protocol only.

\section{Which Pharmaceutical Agents Can Be Considered for Chemoprevention?}

The most promising chemopreventive agents for prostate cancer that have been investigated to date are the 5- $\alpha$ reductase inhibitors (5-ARIs). The enzyme 5- $\alpha$ reductase exists in 2 forms, type 1 and type 2 , and is responsible for the conversion of testosterone to dihydrotestosterone (DHT). DHT is a much more active form of testosterone that acts on the prostate and is involved in pathologic conditions such as benign prostatic hyperplasia (BPH) and prostate cancer. The precise etiology of prostate cancer is largely unknown, although it is considered to be a multifactorial disease that requires the presence of DHT as one of the principle factors. The rational for using 5-ARIs in the prevention of prostate cancer stemmed from the observation that men with a mutation in the $5-\alpha$ reductase enzyme did not develop BPH or prostate cancer. ${ }^{17}$ This observation, combined with a series of epidemiologic data, showed that certain populations of men, such as African Americans, had increased rates of prostate cancer and had higher levels of circulating androgens, higher levels of $5-\alpha$ reductase, and higher levels of dihydrotestosterone. Conversely, Asian men have the lowest rates of prostate cancer incidence and mortality and have lower $5-\alpha$ reductase activity. ${ }^{17}$ Therefore, the first major RCT for the chemoprevention of prostate cancer used the selective type 2 -ARI finasteride in the PCPT trial.

In the PCPT trial 18,882 men 55 years or older were randomized to receive finasteride $5 \mathrm{mg}$ versus placebo once daily over a 7-year period. The group of men selected for were at low risk for prostate cancer because inclusion requirements included a prostate-specific antigen (PSA) $\leq 3 \mathrm{ng} / \mathrm{L}$ and a normal digital rectal examination (DRE). The primary result of the study was the prevalence of prostate cancer in each arm as diagnosed by prostate biopsy for cause (abnormal DRE or PSA $\geq 4$ ) or at the end 
of study. The study showed a $25 \%$ relative reduction ( $6 \%$ absolute reduction) in the prevalence of prostate cancer in the finasteride arm compared with placebo. Rates of sexual side effects (decreased volume of ejaculate, erectile dysfunction, loss of libido, gynecomastia) were higher in the finasteride group. In contrast, urinary side effects (BPH, urgency, frequency, retention, prostatitis) were lower in the finasteride group. The unexpected result was an apparent increase in the prevalence of intermediate- or high-grade cancers (Gleason 7 to 10) among the finasteride group, which were $37 \%$ versus $22 \%$ of the prostate cancers identified in each group, respectively (or, absolute difference of $6.4 \%$ vs $5.1 \%$ of all study participants). There are many possible explanations for this observation, but the most salient question to answer is, Does finasteride induce high-grade cancer or increase the detection of high-grade cancers?

Several additional analyses of the PCPT data support the claim that finasteride increases detection of high-grade prostate cancer and significantly reduces the occurrence of low-grade prostate cancer. When assessing the performance of PSA for patients taking finasteride compared with placebo, Thompson et al ${ }^{18,19}$ found that PSA and DRE were more sensitive at detecting cancers of any grade among patients taking finasteride. It is also known that finasteride reduces prostate size by $25 \%,{ }^{14,20}$ and as such, for the same number of biopsy specimens taken, a larger proportion of the prostate is sampled. If finasteride effectively suppresses the development of low-grade cancers then this will result in the identification of a greater proportion of patients harboring high-grade cancers. Evidence that finasteride does not induce the development of high-grade prostate cancer is offered by Lucia et $\mathrm{al}^{21}$ in their review of the pathologic characteristics of biopsy specimen from the PCPT trial. They found that when comparing biopsies at a given Gleason grade $(\leq 6,7, \geq 8)$, patients in the finasteride arm had a smaller number of cores positive and a smaller percent of each core positive when compared with the placebo arm. In addition, for those patients who were treated with radical prostatectomy after positive biopsy in PCPT, there was no significant difference between treatment and placebo arms in terms of pathologic stage, nodal involvement, or margin status. ${ }^{22}$ Overall, based on results from PCPT, it seems more likely that finasteride increases predictive accuracy of PSA in the detection of prostate cancer and decreases the overall incidence of prostate cancer. Similarly, results from the REDUCE trial seem to support this hypothesis (Table 1).

The REDUCE investigators sought to assess the utility of dutasteride in the prevention of prostate cancer. The theoretical advantage of dutasteride is that it blocks both type 1 and type $25-\alpha$ reductase enzymes compared with finasteride, which blocks only type 1 . Inhibiting both isoenzymes of $5-\alpha$ reductase results in a $90 \%$ decrease in circulating DHT with dutasteride compared with $70 \%$ with finasteride. In addition, type $25-\alpha$ reductase enzyme is thought to be more predominant in prostate cancer cells compared with type 1 . Therefore, dutasteride theoretically can be an effective preventive agent for prostate cancer.

The REDUCE trial randomized 8231 men between the ages of 55 to 75 years with a PSA between 2.5 and $10 \mathrm{ng} / \mathrm{dL}$ and a negative prostate biopsy to receive dutasteride or placebo over a

Table 1. Comparison of the Prostate Cancer Prevention (PCPT), Reduction of Dutasteride of Prostate Cancer Events (REDUCE), and Selenium and Vitamin E Cancer Prevention (SELECT) Trials

\begin{tabular}{|c|c|c|c|c|c|c|c|c|}
\hline & $\begin{array}{l}\text { Patients } \\
\text { (n) }\end{array}$ & $\begin{array}{c}\text { Age } \\
\text { (years) }\end{array}$ & $\begin{array}{c}\text { PSA } \\
\text { (ng/L) }\end{array}$ & $\begin{array}{l}\text { Follow-Up } \\
\text { (years) }\end{array}$ & $\begin{array}{c}\text { Relative Risk } \\
\text { of Prostate } \\
\text { Cancer* }\end{array}$ & $\begin{array}{c}\text { Absolute Risk } \\
\text { of Prostate } \\
\text { Cancer }^{*}\end{array}$ & $\begin{array}{l}\text { Absolute Risk of } \\
\text { High-Grade } \\
\text { Prostate Cancer* }\end{array}$ & $\begin{array}{c}\text { Risk of } \\
\text { Diabetes }\end{array}$ \\
\hline PCPT & 18,883 & $>55$ & $\leq 3$ & 7 & $\downarrow 25 \%$ & $\downarrow 6 \%$ & $\uparrow 0.6 \%$ & $\mathrm{n} / \mathrm{a}$ \\
\hline REDUCE & 8,231 & $55-75$ & $2.5-10$ & 4 & $\downarrow 23 \%$ & $\downarrow 5 \%$ & $0 \%$ to $\uparrow 0.5 \%^{\dagger}$ & $\mathrm{n} / \mathrm{a}$ \\
\hline SELECT & 35,533 & $>50$ & $\leq 4$ & 5.4 & $\begin{array}{c}\uparrow \text { Trend with } \\
\text { vitamin } \mathrm{E}\end{array}$ & $\begin{array}{l}\uparrow \text { Trend with } \\
\text { vitamin } \mathrm{E}\end{array}$ & No known effect & $\begin{array}{l}\uparrow \text { Trend with } \\
\text { selenium }\end{array}$ \\
\hline
\end{tabular}

*Compared with placebo.

${ }^{\dagger}$ Original publication did not demonstrate increased risk of high-grade cancer; however, the Food and Drug Administration mandated re-analysis of biopsy specimen based on modified Gleason score suggesting a $0.5 \%$ increase of high-grade prostate cancer in the dutasteride arm.

PSA, prostate-specific antigen. 
4-year period. This patient population was considered to be at higher risk of having prostate cancer than the population from the PCPT trial. The primary endpoint of the study was biopsy-detectable prostate cancer at 2 and 4 years. Biopsies were performed at study entry, if clinically indicated, or by protocol at 2 and 4 years. The study showed a $23 \%$ decrease in incidence of prostate cancer in the dutasteride group compared with the placebo group (absolute reduction, 5.1\%). There were no statistically significant differences in the presence of Gleason 7 to 10 prostate cancer between the 2 groups. The dutasteride arm also showed lower rates of precancerous histologies on biopsy (highgrade intraepithelial neoplasia and atypical small acinar proliferation) compared with placebo. Similar to the PCPT results, dutasteride was associated with increased sexual side effects and decreased urinary side effects. However, the unexpected result in this study was an increase in the incidence of cardiac failure: $0.7 \%$ among men taking dutasteride compared with $0.4 \%$ of men taking placebo. Two other large RCTs involving 5-ARIs for BPH, the Medical Therapy of Prostatic Symptoms ( $\mathrm{n}=$ $3047)^{23}$ and Combination of Avodart and Tamsulosin $(\mathrm{n}=4838),{ }^{24,25}$ failed to show any increased risk of cardiac events. Therefore, it is generally considered that the very small absolute increase in risk of cardiac failure seen in the REDUCE trial is an artifactual finding of questionable clinical significance. Nonetheless, this may remain a factor when considering large-scale use of dutasteride for prostate cancer prevention.

The American Society of Clinical Oncology and the American Urological Association have provided the only published guideline on the use of 5-ARIs for the prevention of prostate cancer in 2008. ${ }^{26}$ Their recommendations were based on data for a single agent, finasteride, before the publication of data from the REDUCE trial. The guideline concludes that well-informed, asymptomatic men with a PSA $\leq 3.0 \mathrm{ng} / \mathrm{mL}$ who agree to regular screening may benefit from the use of a 5-ARI. However, the guidelines do not recommend the use of 5-ARIs in all men, nor do they suggest a specific trigger to initiate further investigation.

The Food and Drug Administration (FDA) recently has clarified their position with regard to the risk and benefits of 5-ARIs for prostate cancer prevention. ${ }^{27}$ The FDA confirms a $23 \%$ to $25 \%$ relative reduction in overall incidence of prostate can- cer with the use of finasteride or dutasteride. However, they caution that the overall reduction in prostate cancer seems to be primarily with low-risk cancers, and there seems to be a small increase in risk of being diagnosed with high-grade prostate cancer among men who take a 5-ARI. They estimate that one additional man for every 150 to 200 men treated will have a diagnosis of high-grade prostate cancer. In light of these findings the FDA did not approve the use of 5-ARI for the prevention of prostate cancer.

Other medications such as NSAIDS, Cox 2 inhibitors, and the SERM toremifene have been studied for prostate cancer prevention. In a large, case control study $(\mathrm{n}=1298)$, Irani et $\mathrm{al}^{28}$ did not find any protective effect of NSAIDS on prostate cancer. However, a review of the topic by Basler and Piazza ${ }^{29}$ did identify several case-control and cohort studies that suggest a protective effect of NSAID use on prostate cancer. To date there are no RCTs investigating the use of NSAIDS for prevention of prostate cancer. Cox 2 inhibitors have been shown to reduce polyp size in colorectal cancer and seemed to be promising for prostate cancer prevention. ${ }^{29}$ However, an industry-sponsored phase III RCT of rofecoxib was aborted after the medication was withdrawn from market. ${ }^{30}$ Toremifene was studied in a phase II RCT for prevention of prostate cancer in men with high-risk pathologic features on prostate biopsy. The investigators found a $48 \%$ decreased incidence of prostate cancer with $20 \mathrm{mg}$ toremifene daily compared with placebo and a favorable tolerability profile after 1 year. ${ }^{31}$ However, there are no published phase III trials evaluating the role of toremifene as a preventive agent for the incidence of prostate cancer. Interestingly, toremifene currently is being evaluated in 2 phase III trials of men with prostate cancer receiving androgen deprivation therapy. Interim analysis suggests potential benefit with regard to decreased bone loss and improved lipid profile. ${ }^{32,33}$ Generally, the use of NSAIDs and Cox 2 inhibitors do not seem to have a role in prostate cancer prevention, and the use of SERMs may be a potential option among high-risk populations in the future.

The use of statins also seems promising in the prevention of prostate cancer. A recently published meta-analysis that reviewed a secondary analysis of 6 large RCTs and 13 observational studies concluded that statin use was not associated with over- 
all prostate cancer incidence but was associated with a decrease in the incidence of advanced prostate cancer (relative risk, 0.77; 95\% CI, 0.64$0.93) .{ }^{34}$ These findings have been repeated consistently in smaller cohort and case control studies. Therefore, from the available evidence it seems that statins may play a role in the chemoprevention of aggressive prostate cancers in the future. However, to date our best evidence relies on secondary endpoints of large studies performed to assess the cardiovascular benefits of statins. There has been no RCT designed to primarily assess the role of statins in the prevention of prostate cancer.

\section{Are Dietary Supplements or Diet Modification Effective for Prostate Cancer Prevention?}

A multitude of dietary supplements have been evaluated for the prevention of prostate cancer, the best studied of which are selenium and vitamin $\mathrm{E}(\alpha-$ tocopherol). Both selenium and vitamin $\mathrm{E}$ are essential nutrients in human health. Their potential role in prostate cancer prevention was made relevant clinically by unexpected findings from 2 large cancer prevention trials. ${ }^{35}$ The Nutritional Prevention of Cancer Study was designed to evaluate the role of selenium in the secondary prevention of skin cancer. In subanalyses of patients who received selenium, the study revealed a $66 \%$ reduction in prostate cancer incidence over 4.5 years, ${ }^{36}$ which continued to show a $49 \%$ reduction after 7.5 years. ${ }^{37}$ Similarly, the secondary analysis of the $\alpha$ Tocopherol Beta Carotene Cancer Prevention trial, designed to evaluate the effect of vitamin $\mathrm{E}$ on lung cancer, found a $32 \%$ reduction in prostate cancer incidence among patients in the vitamin $\mathrm{E}$ arm. ${ }^{38}$ Based on these trials and other supporting studies, the SELECT trial was designed.

The SELECT trial randomized 35,533 men $\geq 50$ years of age with a PSA $\leq 4 \mathrm{ng} / \mathrm{mL}$ and a nonsuspicious DRE. These men were assigned randomly to 1 of 4 groups: selenium, vitamin E, selenium and vitamin $\mathrm{E}$, or placebo. After a median follow-up of 5.4 years the study was stopped because a conclusive finding of $P<.0001$ was reached, showing no difference in incidence of prostate cancer across all arms of the trial. In fact, there was a trend $(P=.06)$ toward increased incidence of prostate cancer in the vitamin $\mathrm{E}$ arm and increased occurrence of type 2 diabetes in the selenium arm. Selenium also was associated with in- creased rates of alopecia and grades 1 and 2 dermatitis $(P<.01)$. In 2 meta-analyses, high-dose vitamin $\mathrm{E}$ supplementation has been associated with increased all-cause mortality, ${ }^{39,40}$ although the Physician's Health Study II, a well-designed RCT, did not reproduce this finding. ${ }^{41}$ Therefore, there is no evidence that selenium or vitamin $\mathrm{E}$, in their $\alpha$-tocopherol forms, have any benefit in prostate cancer prevention.

Other supplements and diet regimens have been evaluated in RCTs and population-based cohort studies. Vitamin A (beta carotene), vitamin C, and multivitamins have been investigated in the setting of large RCTs. Unfortunately, to date these trials have not provided adequate evidence to recommend their use for prostate cancer prevention. ${ }^{42-44}$ Soy, animal products, calcium, protein, green tea, folic acid, lycopene, and fish consumption all have been evaluated in multiple population and cohort studies, but have failed to yield clear enough results from which to base phase III clinical trials. ${ }^{19,45-48}$ Chavarro et $\mathrm{al}^{46}$ performed a prospective cohort study based on the Physician's Health Study and found that fish consumption ( $\geq 5$ times per week) was not related to prostate cancer risk but was protective of prostate cancer-specific death. Much attention has been given to the use of lycopene based on the result of the Health Professionals Follow-up Study, which demonstrated a decreased risk of prostate cancer with increasing consumption of tomato sauce. ${ }^{49}$ However, the Prostate Lung Colorectal and Ovarian Cancer study failed to identify an overall protective effect of lycopene on prostate cancer incidence. ${ }^{50}$ It may be that some of these dietary supplements have a beneficial effect in specific populations or clinical situations. However, at this time there is inadequate evidence to recommend any nutritional supplement or dietary regimen for the prevention of prostate cancer (Table 2).

\section{Conclusion and Recommendation}

The prevalence of prostate cancer and the significant morbidity and cost associated with its treatment make it an ideal target for prevention. Many pharmaceutical and nutritional interventions have been investigated. At present there is no suitable evidence to recommend using any specific nutritional supplement or diet to prevent prostate cancer. However, high meat protein and high-fat diet have been associated with increased risk of prostate 
Table 2. A Summary of Proposed Agents for the Prevention of Prostate Cancer, Mechanisms, Demonstrated Benefits, Potential Harm and Quality of Evidence

\begin{tabular}{|c|c|c|c|c|}
\hline Agents & Proposed Mechanism* & Demonstrated Benefit & Potential Harm & $\begin{array}{l}\text { Quality of } \\
\text { Evidence }^{\dagger}\end{array}$ \\
\hline Finasteride & $\begin{array}{l}\text { Inhibits 5-alpha reductase, } \\
\text { lowers DHT }\end{array}$ & $\begin{array}{l}\text { Decreased incidence/diagnosis } \\
\text { of prostate cancer, } \\
\text { improved urinary symptoms }\end{array}$ & $\begin{array}{l}\text { Increased sexual side effects, } \\
\text { may increase risk of high- } \\
\text { grade prostate cancer }\end{array}$ & Level 1 \\
\hline Dutasteride & $\begin{array}{l}\text { Inhibits 5-alpha reductase, } \\
\text { lowers DHT }\end{array}$ & $\begin{array}{l}\text { Decreased incidence/diagnosis } \\
\text { of prostate cancer, } \\
\text { improved urinary symptoms }\end{array}$ & $\begin{array}{l}\text { Increased sexual side effects, } \\
\text { may increase risk of high- } \\
\text { grade prostate cancer }\end{array}$ & Level 1 \\
\hline Selenium & $\begin{array}{l}\text { Inhibits clonal expansion } \\
\text { of prostate cancer cells }\end{array}$ & No effect & $\begin{array}{l}\text { May increase type II } \\
\text { diabetes mellitus }\end{array}$ & Level 1 \\
\hline Vitamin E & $\begin{array}{l}\text { Cell membrane } \\
\text { antioxidant }\end{array}$ & No effect & $\begin{array}{l}\text { May increase prostate } \\
\text { cancer incidence, all cause } \\
\text { mortality, and } \\
\text { hemorrhagic stroke }\end{array}$ & Level 1 \\
\hline Vitamin C & Antioxidant & No effect & No effect & Level 2 \\
\hline Beta-carotene & Antioxidant & No effect & $\begin{array}{l}\text { Increased risk of lung and } \\
\text { gastric cancers }\end{array}$ & Level 2 \\
\hline Multivitamins & Various mechanisms & No effect & $\begin{array}{l}\text { May increase rate of } \\
\text { prostate specific death }\end{array}$ & Level 2 \\
\hline Lycopene & Antioxidant & $\begin{array}{l}\text { Possible effect but conflicting } \\
\text { evidence }\end{array}$ & Unknown & Level 2 \\
\hline NSAIDs & $\begin{array}{l}\text { Reduces prostaglandin } 2 \\
\text { and arachidonic acid }\end{array}$ & $\begin{array}{l}\text { Unclear effect on prostate } \\
\text { cancer incidence }\end{array}$ & Increased risk GI bleed & Level 3 \\
\hline Aspirin & Inhibit cell migration & $\begin{array}{l}\text { May decrease risk of prostate } \\
\text { cancer }\end{array}$ & Increased risk GI bleed & Level 3 \\
\hline Cox 2 inhibitors & Pro-apoptotic agent & No effect & $\begin{array}{l}\text { Risk of cardiovascular } \\
\text { events at high dose }\end{array}$ & Level 3 \\
\hline Statins & $\begin{array}{l}\text { Multiple potential } \\
\text { cholesterol and non- } \\
\text { cholesterol-dependent } \\
\text { mechanisms }\end{array}$ & $\begin{array}{l}\text { May lower incidence of } \\
\text { advanced prostate cancer }\end{array}$ & $\begin{array}{l}\text { Myalgia, hepatic } \\
\text { dysfunction }\end{array}$ & Level 3 \\
\hline Toremifene & $\begin{array}{l}\text { Selective estrogen } \\
\text { receptor modulator }\end{array}$ & $\begin{array}{l}\text { May decrease incidence of } \\
\text { prostate cancer }\end{array}$ & $\begin{array}{l}\text { Hot flashes, nausea, hepatic } \\
\text { dysfunction }\end{array}$ & Level 3 \\
\hline Soy & Weak estrogen & $\begin{array}{l}\text { Increased intake may decrease } \\
\text { prostate caner risk }\end{array}$ & Unknown & Level 3 \\
\hline Protein/meat intake & $\begin{array}{l}\text { Unknown; may be related } \\
\text { to fat intake }\end{array}$ & $\begin{array}{l}\text { Lowering meat intake has not } \\
\text { been shown lower cancer } \\
\text { risk }\end{array}$ & $\begin{array}{l}\text { Increased red meat intake } \\
\text { may have increased risk } \\
\text { of prostate cancer }\end{array}$ & Level 3 \\
\hline Fat intake & $\begin{array}{l}\text { Fat increases circulating } \\
\text { androgen }\end{array}$ & $\begin{array}{l}\text { Conflicting evidence for } \\
\text { lowering fat intake on } \\
\text { prostate cancer, but } \\
\text { documented benefit to } \\
\text { cardiovascular health }\end{array}$ & $\begin{array}{l}\text { High-fat diets are associated } \\
\text { with higher incidence and } \\
\text { more advanced prostate } \\
\text { cancer }\end{array}$ & Level 3 \\
\hline Fish consumption & $\begin{array}{l}\text { Via modifying omega } 3 \text { : } \\
\text { omega } 6 \text { fatty acid ratio }\end{array}$ & $\begin{array}{l}\text { Increased fish intake may } \\
\text { decrease prostate cancer } \\
\text { death }\end{array}$ & Unknown & Level 3 \\
\hline
\end{tabular}

*There are no clearly identified causal mechanisms for prostate cancer prevention; commonly accepted mechanisms with some evidence from preclinical investigations are presented.

${ }^{\dagger}$ Levels of evidence employ the strength of recommendation taxonomy (SORT) as described in Ebell MH, Siwek J, Weiss BD, et al. Strength of recommendation taxonomy (SORT): a patient-centered approach to grading evidence in the medical literature. J Am Board Fam Pract 2004;17:59-67.

DHT, dihydrotestosterone; GI, gastrointestinal; NSAIDs, nonsteroidal anti-inflammatory drugs.

cancer retrospectively. Unfortunately, lowering meat or fat consumption has not shown benefit with regard to the development of prostate cancer, but it does have clear cardiovascular benefits. The strongest evidence exists to support the use of
5-ARIs for chemoprevention of prostate cancer; however, this indication has not been approved by the FDA. We therefore recommend that, for patients who wish to take a proactive approach to prostate cancer and have an enlarged prostate with 
voiding symptoms, the only class of medications that can be offered for prevention are 5-ARIs. Men with an enlarged prostate and voiding symptoms may derive the additional benefit of chemoprevention and improved urinary symptoms with the use of a 5-ARI. Men who are taking a 5-ARI should be followed with yearly PSAs and should be made aware of the potential risks, side effects, and benefits that can be anticipated from treatment. A baseline PSA measure should be obtained before the start of therapy with a 5-ARI, and physicians should expect this value to drop by approximately $50 \%$ at 6 months. Any persistent rise in PSA while taking a 5-ARI should be considered suspicious and prostate cancer should be ruled out. ${ }^{27}$

\section{Gaps in the Knowledge}

Many aspects of prostate cancer chemoprevention are not well understood. The use of 5-ARIs have shown some benefit, but the optimal duration of therapy and long-term benefit have yet to be defined. In addition, their side effect profile may be unacceptable to some men. There remains a need to investigate the use of other agents that can be effective in the prevention of prostate cancer but may be better tolerated. There are ongoing clinical trials of lycopene, soy, green tea, omega 3 fatty acids, and polyunsaturated fatty acids (www.clinicaltrials.gov). However, these trials are designed to evaluate surrogate makers for the development of prostate cancer and are not powered to examine incidence. As such, they are unlikely to yield a result of clinical significance. In addition, cost-effectiveness studies will be needed to determine the feasibility of using a 5-ARI or another agent on a large scale.

\section{Key Points}

- Prostate cancer prevention can be offered to well-informed men who wish to take a proactive approach but should not be offered systematically to all men.

- Only finasteride and dutasteride have been studied adequately to be recommended for use in prostate cancer prevention selectively with highly motivated patients.

- Any rise in PSA while taking a 5-ARI should be considered suspicious and prostate cancer should be ruled out.

\section{References}

1. American Cancer Society. Cancer facts and figures, 2010. Atlanta, GA: American Cancer Society; 2010.

2. American Cancer Society. Breast cancer facts and figures, 2010. Atlanta, GA: American Cancer Society; 2010.

3. Altekruse SF, Kosary CL, Kracho M, et al. SEER cancer statistics review, 1975-2007. Bethesda, MD: National Cancer Institute. Available at http://seer. cancer.gov/csr/1975_2007/. Accessed November 14, 2011.

4. Bill-Axelson A, Holmberg L, Ruutu M, et al. Radical prostatectomy versus watchful waiting in early prostate cancer. N Engl J Med 2005;352:1977-84.

5. Bolla M, Gonzalez D, Warde P, et al. Improved survival in patients with locally advanced prostate cancer treated with radiotherapy and goserelin. N Engl J Med 1997;337:295-300.

6. Bolla M, Collette L, Blank L, et al. Long-term results with immediate androgen suppression and external irradiation in patients with locally advanced prostate cancer (an EORTC study): a phase III randomised trial. Lancet 2002;360:103-6.

7. Crawford ED, Eisenberger MA, McLeod DG, et al. A controlled trial of leuprolide with and without flutamide in prostatic carcinoma. $\mathrm{N}$ Engl J Med 1989;321:419-24.

8. Tannock IF, deWit R, Berry WR, et al. Docetaxel plus prednisone or mitoxantrone plus prednisone for advanced prostate cancer. N Engl J Med 2004;351: 1502-12.

9. Tran C, Ouk S, Clegg NJ, et al. Development of a second generation antiandrogen for treatment of advanced prostate cancer. Science 2009;324: 787-90.

10. Smith MR, Egerdie B, Toriz NH, et al. Denosumab in men receiving androgen-deprevation therapy for prostate cancer. N Engl J Med 2009;361:745-75.

11. Sonpavde G, Periman PO, Bernold D, et al. Sunitinib malate for metestatic castration-resistant prostate cancer following docetaxel-based chemotherapy. Ann Oncol 2010;21:319-24.

12. Sanda MG, Dunn RL, Michalski J, et al. Quality of life and satisfaction with outcome among prostate cancer survivors. N Engl J Med 2008;358:1250-61.

13. Wilson LS, Tesoro R, Elkin EP, et al. Cumulative cost pattern comparison of prostate cancer treatments. Cancer 2007;109:518-27.

14. Thompson IM, Goodman PJ, Tangen CM, et al. The influence of finasteride on the development of prostate cancer. N Engl J Med 2003;349:215-24.

15. Andriole GL, Bostwick DG, Brawley OW, et al. Effect of dutasteride on the risk of prostate cancer. N Engl J Med 2010;362:1192-202.

16. Lippman SM, Klein EA, Goodman PJ, et al. Effect of selenium and vitamin $\mathrm{E}$ on risk of prostate cancer and other cancers. JAMA 2009;301:39-51. 
17. Thompson IM, Kouril M, Klein EA, Coltman CA, Ryan A, Goodman PJ. The prostate cancer prevention trial: current status and lessons learned. Urology 2001;57(Suppl 4A):230-4.

18. Thompson IM, Chi C, Ankerst DP, et al. Effect of finasteride on the sensitivity of PSA for detecting prostate cancer. J Natl Cancer Inst 2006;98:1128-33.

19. Thompson IM, Tangen CM, Goodman PJ, et al. Finasteride improves the sensitivity of digital rectal examination for prostate cancer detection. J Urol 2007;177:1749-52.

20. McConnell JD, Reohrborn CG, Bautista OM, et al. The long term effect of doxazosin, finastaride, and combination therapy on the clinical progression of benign prostatic hyperplasia. N Engl J Med 2003; 349:2387-98.

21. Lucia MS, Darke AK, Goodman PJ, et al. Pathologic characteristics of cancers detected in the prostate cancer prevention trial: implications for prostate cancer detection and chemoprevention. Cancer Prev Res 2008;1(3):167-73.

22. Kramer BS, Hagerty LK, Justman S, et al. Use of 5 alpha reductase inhibitors for prostate cancer chemoprevention: American Society of Clinical Oncology/American Urological Association 2008 clinical practice guideline. J Urol 2009;181:1642-57.

23. McConnell JD, Roehrborn CG, Bautista OM, et al. The long term effect of doxazosin, finasteride, and combination therapy on the clinical progression of benign prostatic hyperplasia. N Engl J Med 2003; 349:2387-9.

24. Roehrborn CG, Siami P, Barkin J, et al. The effects of dutasteride, tamsulosin and combination therapy on lower urinary tract symptoms in men with benign prostatic hyperplasia and prostatic enlargement: 2-year results from the CombAT study. J Urol 2008; 179:616-21.

25. Barkin J, Reohrborn CG, Siami P, et al. Effect of dutasteride, tamsulosin and the combination on patient-reported quality of life and treatment satisfaction in men with moderate-to-severe benign prostatic hyperplasia: 2-year data from the CombAT trial. BJU Int 2009;103:919-26.

26. Kramer BS, Hagerty KL, Justman S, et al. Use of 5 alpha-reductase inhibitors for prostate cancer chemoprevention: American Society of Clinical Oncology/ American Urological Association 2008 clinical practice guideline. J Clin Oncol 2009;27:1502-1516.

27. Theoret MR, Ning YM, Zhang JJ, Justice R, Keegan $\mathrm{P}$, Pazdur R. The risks and benefits of $5 \alpha$ reductase inhibitors for prostate-cancer prevention. N Engl J Med 2011;365:97-9.

28. Irani J, Ravery V, Pariente JL, et al. Effect of nonsteroidal anti-inflammatory agents and finasteride on prostate cancer risk. J Urol 2002;168:1985-8.

29. Basler JW, Piazza GA. Nonsteroidal anti-inflammatory drugs and cyclooxygenase-2 selective inhibitors for prostate cancer chemoprevention. J Urol 2004; 171:S59-63.

30. Thompson IM. Chemoprevention of prostate cancer: agents and study designs. J Urol 2007;178:S9-13.

31. Price D, Stin B, Seiber P, Tutrone R, Bailen J, Goluboff E. Toremifene for the prevention of prostate cancer in men with high grade prostatic intraepithelial neoplasia: results of a double blind, placebo controlled, phase IIB clinical trial. J Urol 2006; 176:965-71.

32. Smith MR, Malkowicz BS, Chu F, et al. Toremifene improves lipid profiles in men receiving androgendeprivation therapy for prostate cancer: interim analysis of a multineter phase III study. J Clin Oncol 2008;26:1824-9.

33. Smith MR, Malkowicz BS, Chu F, et al. Toremifene increases bone density in men receiving androgendeprivation therapy for prostate cancer: interim analysis of a multineter phase III study. J Urol 2008; 179:152-5.

34. Bonovas S, Filioussi K, Sitaras NM. Statin use and the risk of prostate cancer: a meta-analysis of 6 randomized clinical trials and 13 observational studies. Int J Cancer 2008;123(4):899-904.

35. Klein EA. Selenium and vitamin E cancer prevention trial. Ann N Y Acad Sci 2004;1031:234-41.

36. Clark LC, Combs GF, Turnbull BW, et al. Effects of selenium supplementation for cancer prevention in patients with carcinoma of the skin: a randomized controlled trial. Nutritional Prevention of Cancer Study Group. JAMA 1996;276:1957-63.

37. Duffield-Lillico AJ, Dalkin BL, Reid ME, et al. Selenium supplementation, baseline plasma selenium status and incidence of prostate cancer: an analysis of the complete treatment period of the Nutritional Prevention of Cancer Trial. BJU Int 2003;91:608-12.

38. ATBC Cancer prevention study group. The effect of vitamin $\mathrm{E}$ and beta carotene on the incidence of lung cancer and other cancers in male smokers. N Engl J Med 1994;330:1029-35.

39. Miller ER III, Pastor-Barriuso R, Dalal D, Riemersma RA, Appel LJ, Guallar E. Meta-analysis: highdosage vitamin $\mathrm{E}$ supplementation may cause increased all-cause mortality. Ann Intern Med 2005; 142(1):37-46.

40. Bjelakovic G, Nikoloova D, Gluud, LL, Simonetti RG, Gluud C. Mortality in randomized trials of antioxidant supplements for primary and secondary prevention: systematic review and meta-analysis. JAMA 2007;297(8):842-57.

41. Sesso HD, Buring JE, Christen WG, et al. Vitamins $\mathrm{E}$ and $\mathrm{C}$ in the prevention of cardiovascular disease in men: the Physicians' Health Study II randomized controlled trial. JAMA 2008;300:2123-33.

42. Gaziano MJ, Glynn RJ, Christen WG, et al. Vitamins $\mathrm{E}$ and $\mathrm{C}$ in the prevention of prostate and total cancer in men: the Physicians' Health Study II randomized controlled trial. JAMA 2009;301(1):52-62. 
43. Druesne-Pecollo N, Latino-Martel P, Norat T, et al. Beta-carotene supplementation and cancer risk: a systematic review and metaanalysis of randomized controlled trials. Int J Cancer 2009;127:172-84.

44. Stevens VL, McCullough ML, Diver RW, et al. Use of multivitamins and prostate cancer mortality in a large cohort of US men. Cancer Causes Control 2005;16:643-50.

45. Schuurman AG, van den Brandt PA, Dorant E, Goldbohm RA. Animal products, calcium and protein and prostate cancer risk in The Netherlands Cohort Study. Br J Cancer 1999;80:1107-13.

46. Chavarro JE, Stampfer MJ, Hall MN, Sesso HD, Ma J. A 22-y prospective study of fish intake in relation to prostate cancer incidence and mortality. Am J Clin Nutr 2008;88:1297-303.
47. Klein EA, Thompson IM. Update on chemoprevention of prostate cancer. Curr Opin Urol 2004;14: 143-9.

48. Moyad MA, Sakr WA, Hirano D, Miller GJ. Complementary medicine for prostate cancer: effects of soy and fat consumption. Rev Urol 2001;3(Suppl 2):S20-30.

49. Giovannucci E, Rimm EB, Liu Y, Stampfer MJ, Willett WC. A prospective study of tomato products, lycopene, and prostate cancer risk. J Natl Cancer Inst 2002;94:391.

50. Kirsh VA, Mayne ST, Peters U, et al. A prospective study of lycopene and tomato product intake and risk of prostate cancer. Cancer Epidemiol Biomarkers Prev 2006;15:92. 